\title{
MAKNA KONTEKSTUAL BAHASA IKLAN ROKOK DI TELEVISI
}

\author{
Suryanti \\ Program Studi Pendidikan Bahasa dan Sastra Indonesia, Universitas \\ Muhammadiyah Buton \\ Email: suryanti042516@gmail.com
}

\begin{abstract}
ABSTRAK
Masalah yang dikemukakan adalah "Teks iklan rokok apa sajakah yang memiliki makna kontekstual, makna apa sajakah yang terkandung dalam teks iklan rokok tersebut“. Tujuan penelitian ini adalah untuk menemukan teks iklan rokok yang memiliki makna kontekstual, menjelaskan makna yang terkandung dalam teks iklan rokok tersebut. Manfaat dalam penelitian ini adalah salah satunya dengan perkembangan ilmu bahasa periklanan khususnya kajian semantik akan diperoleh gambaran jelas mengenai makna kontekstual yang dibentuk oleh iklan rokok. Metode yang digunakan dalam penelitian ini adalah metode deskriptif kualitatif. Metode tersebut bertujuan untuk mendeskripsikan secara sistematis, aktual, tajam, dan akurat. Penelitian ini merupakan penelitian lapangan yang menggunakan pendekatan semantik. Teknik pengumpulan data yang digunakan penulis dalam penelitian ini yaitu dengan cara rekam, simak dan catat. Dalam menganalisis penulis menggunakan beberapa tahap yaitu mengumpulkan data, pengklasifikasian data, mencatat data pada kartu data, menganalisis dan mengambil simpulan. Berdasarkan hasil penelitian, dapat disimpulkan bahwa iklan merupakan sarana penyampain suatu produk terhadap khalayak. Bahasa dalam iklan ini dikatakan sebagai bahasa iklan yang tidak terlepas dari faktor sosial dan situasional seperti halnya iklan rokok yang slogannya tidak ada keterkaitannya dengan rokok. Penayangan iklan rokok di Televisi di tampilkan pada malam hari dimulai sekitar pukul 22.00 WITA. Alasan yang paling mendasar dari penayangan tersebut karena tontonan tersebut diperuntukkan khusus untuk orang dewasa.
\end{abstract}

\section{Kata Kunci: Iklan, Televisi, Iklan Televisi}

\section{PENDAHULUAN}

Iklan merupakan kegiatan komunikasi antara produsen dan khalayak yang bersifat mengajak. Pesan produsen disampaikan melalui iklan dalam bentuk bahasa media. Iklan hadir dalam berbagai media, seperti majalah, radio, koran dan televisi. Penelitian ini memiliki beberapa tujuan yang ingin dicapai, yaitu 
sebagai berikut: 1. Menemukan Teks iklan rokok yang memiliki makna kontekstual; 2 Menjelaskan makna yang terkandung dalam teks iklan rokok;

Definisi Operasional digunakan untuk menghindari berbagai penafsiran yang menyimpang dalam penelitian ini, berikut ini dikemukakan beberapa batasan istilah: (1) Makna kontekstual adalah makna yang timbul akibat adanya hubungan antar konteks sosial dan situasional dengan bentuk ujaran yang terbentuk karena terdapat setting, kegiatan, dan relasi; (2) Bahasa iklan rokok adalah slogan dalam iklan rokok di televisi yang berisi pesan dan bersifat menarik untuk mempengaruhi konsumen; (3) Iklan adalah sebuah pesan yang menawarkan produk rokok yang ditujukan kepada masyarakat melalui media televisi; (4) Televisi adalah media yang digunakan untuk memperoleh data.

\section{LANDASAN TEORI}

Kridalaksana (1992) dalam Chaer dan Aminuddin mendefinisikan bahasa sebagai sistem lambang bunyi yang arbitrer yang digunakan oleh para anggota kelompok sosial untuk bekerja, berinteraksi, dan mengidentifikasikan diri.

Bahasa bagi sebagian masyarakat tidak lebih dari sekedar alat komunikasi yang mereka peroleh secara tidak disadari, terus berkembang sejalan dengan perkembangan kehidupan (Alwasilah, 2003:55).

Verhaar (1998:124) menyebutkan bahwa semantik berarti teori makna atau teori arti, yakni cabang semantik bahasa yang menyelidiki makna atau arti. Sosiologi memiliki kepentingan dengan semantik karena sering dijumpai kenyataan bahwa penggunaan kata-kata tertentu untuk menyatakan suatu makna dapat menandai suatu kelompok dalam masyarakat (Chaer, 2002:4). Fokus penelitian ini adalah semantik (makna), khususnya makna kontekstual dalam 
bahasa iklan rokok yang terdapat di televisi. Chaer (2002:12) menyatakan bahwa pengetahuan semantik akan memberikan manfaat teoritis juga manfaat praktis. Makna kontekstual menurut Chaer (2003:290) adalah makna leksem atau kata yang berada di dalam satu konteks.Makna konteks dapat pula berkenaan dengan situasinya yakni tempat, waktu dan lingkungan penggunaan bahasa itu. Sebagai contoh pada slogan iklan rokok Sampoerna Hijau:

“nggak ada loe, nggak rame!"

Slogan tersebut jika dilontarkan di kampus sewaktu ada perkumpulan mahasiswa, tentu jawabannya akan lain jika dibandingkan dengan situasi perokok yang tidak mau menghabiskan kenikmatan merokok bersama teman-temannya, “nggak ada loe, nggak rame!” sambil memegang rokok tersebut. Berbeda halnya jika slogan di atas dilontarkan dalam situasi kampus sewaktu ada perkumpulan antarmahasiswa. Maksud dari slogan “nggak ada loe, nggak rame!” tentu akan mengacu pada salah satu orang yang ketika orang tersebut tidak hadir dalam perkumpulan itu, maka situasinya akan sepi, nggak rame.

Rhenald Kasali (1995 dalam puspita, 2001:2) mendefinisikan iklan sebagai pesan yang menawarkan produk yang ditujukan kepada masyarakat melalui suatu media. Untuk menyampaikan pesan tersebut kepada konsumen, maka digunakan suatu alat, salah satunya adalah bahasa.Disamping bahasa, masih banyak alat komunikasi dalam periklanan, diantaranya gambar, bunyi, dan suara. Bahasa iklan dikatakan ekspresif karena dia harus secara benar dan tepat mengungkapkan dengan istimewa pesan pesan yang ingin disampaikan.Bahasa iklan dikatakan impresif, karena pesan itu mesti diusahakan agar selalu di ingat konsumen serta berkesan simpatik (Charlie, 1999:39). Karena itu tidaklah heran 
jika bahasa iklan diciptakan "unik”, misalnya iklan rokok.Para produsen rokok tentu menyadari hal itu.

Dalam iklan rokok tidak ada yang mempropagandakan, hisaplah rokok A karena kandungan nikotinnya menyehatkan badan, meningkatkan vitalitas, membuat kulit terang bercahaya, dan menghisapnya menjadi orang bijaksana. Iklan rokok berbeda dengan iklan lain, seperti yang sering ditayangkan di televisi.

\section{METODE PENELITIAN}

Metode penelitian ini adalah metode deskriptif kualitatif. Dengan metode ini, peneliti berusaha untuk memaparkan hasil penelitian mengenai bahasa iklan rokok televisi yang dikaji berdasarkan kajian semantik. Jenis penelitian ini adalah jenis penelitian lapangan dengan menggunakan pendekatan semantik. Penelitian ini bertujuan untuk mendeskrispsikan makna kontekstual bahasa iklan rokok di televisi. Data dalam penelitian di ambil dengan cara direkam, dicatat, dan disimak. Sumber data dalam penelitian ini bersumber dari media televisi dalam beberapa siaran. Teknik pengumpulan data yang dilakukan dalam penelitian ini adalah sebagai berikut: (1) Teknik Rekam, (2) Teknik Simak, (3) Teknik Catat, Dalam menganalisis data penelitian, penulis melakukan beberapa tahap analisis data, diantaranya: (1) Mengumpulkan data, yaitu berupa pencarian, pengumpulan dan pemilihan data sesuai dengan masalah yang akan diteliti; (2) Pengklasifikasian data, yaitu mengelompokkan data yang telah terkumpul untuk memudahkan proses analisis; (3) Mengambil simpulan, merupakan hasil akhir sekaligus jawaban tujuan penelitian ini.

\section{HASIL DAN PEMBAHASAN}


Deskripsi ini merupakan transkripsi audio visual iklan rokok di televisi menjadi bentuk tulisan.

1. Iklan rokok GG Signature

Slogan signature moment

2. Iklan rokok Dji Sam Soe/234

Slogan mahakarya Indonesia. Adapun kutipan iklan tersebut adalah:

"Indonesia bangsa yang rekat"

"Yang satu mimpi"

"Walau terbagi suku”

"Kita membuka telinga"

"Untuk semua teladan"

"Kita akan senantiasa"

"Dan mengasa sebuah keahlian rasa"

"Kita merendahkan hati"

"Kita melompat"

"Kita melangkah mantap"

"Satu demi satu, demi satu"

"Setiap helai benang dan torehan"

"Setiap tetes dan gerakan"

"Untuk menikmati aroma keberhasilan"

"Kita bersama terus"

"Kita menambah kualitas diri"

"Dan menjaganya agar tak pernah berubah"

"Kita tampilkan sendiri"

"Karna kapal ini untuk semua teladan"

"Kita bergotong royong"

"Lihatlah sesuatu yang dimulai dari dalam"

"Tak luntur terkikis waktu"

"Inilah jiwa Indonesia"

"Jiwa yang menciptakan"

"Mahakarya"

3. Iklan rokok Dunhill Filter

Slogan taste the power

4. Iklan rokok Djarum 76 Filter Gold

Slogannya adalah yang penting hepi. Dalam iklan rokok tersebut

menampilkan beberapa dialog. Kutipan kalimat dalam iklan tersebut: “Gadis: Aku

pengen teman hidup yang baik, pengertian, sabar, penurut dan yang penting setia “.

"Jin: Humm... ok".

5. Iklan rokok Magnum Filter 
Slogan dalam iklan rokok adalah inspirasi tanpa batas. Kutipan kalimat dalam iklan tersebut:

"Pelayanan kelas dunia"

"Pemandangan indah"

"Semua yang diinginkan tersedia"

"Inilah yang menjadi inspirasiku”

"Dengan menikmati indahnya kota bersama teman"

"Yang memahami warna hatinya"

"Ini baru pengalaman pertamaku"

6. Iklan rokok U Mild

Slogan iklan rokok adalahcowo lebih tau. Kutipan kalimat dalam iklan tersebut:

"Yang dijalani semua orang”

“Ada beberapa aturan yang tak tertulis tapi jadi panutan”

“Adahal yang cuma cowo yang lebih karna cowo punya cara mainnya”

“Kita tau cowo wajib punya mainan”

“Kita tau jalan jangan lupa punya pengaman”

"Kita juga tau cowo selalu siap buat teman”

"Kita tau semua itu karna cowo itu lebih tau”

7. Iklan rokok Dunhill Mild

Slogan dalam iklan rokok adalah discover fine taste. Kutipan kalimat dalam

iklan tersebut:

"Buah perjalanan"

"Perjalanan untuk mencari hal terbaik"

"Temukan yang terbaik dengan satu tujuan pasti”

"Cita rasa istimewa”

8. Iklan rokok Sampoerna A Mild

Slogan go ahead

Kutipan kalimat dalam iklan tersebut:

"Kita harus benar lupa dengan binar cahaya"

"kita bergerak bersama mengikuti arus"

"Tau banyak hal"

"Kita menatap pesona kepada dunia luar"

"Kita adalah singa"

'Berkuasa ditengah rimba” 
"Lihat bahkan bertaruh seperti bebekpun dia akan menarik"

" kita ingin bebas untuk melihat"

"Namun jangan pernah lupa”

"Kita adalah manusia"

9. Iklan rokok Gudang Garam Gold

Slogan cita rasa tinggi dengan sentuhan emas. Kutipan kalimat dalam iklan tersebut:

"Perjalanan panjang dari segala penjuru"

"Tak merubah dan bahannya berkualitas tinggi"

"Demi satu kenikmatan yang tiada tara"

"Cita rasa tinggi dengan sentuhan emas"

Analisis data terdiri atas analisis data teks iklan rokok.

1. Analisis Iklan rokok GG Signature

Slogan iklan rokok GG Signature adalah Signature Moment. Situasi yang terjadi dalam iklan rokok tersebut yaitu seorang pemuda melakukan terjun payung di angkasa memakai parasut melewati tebing hingga sampai ketempat tujuan dengan waktu yang begitu singkat. Slogan iklan rokok GG Signature menggunakan istilah asing yaitu Signature Moment. Jika dimaknai secara leksikal, signature berarti berasal dari bahasa Inggris yang berarti singkat sedangkan moment juga berasal dari bahasa Inggris yang berarti waktu. Apabila kedua kata tadi digabungkan menjadi signature moment, yang berarti waktu singkat. Dilihat dari segi penyampaiannya iklan tersebut disampaikan dalam bentuk monolog.

\section{Analisis Iklan rokok Dji Sam Soe/234}

Slogan mahakarya Indonesia. Situasi yang terjadi dalam iklan rokok tersebut yaitu menjelaskan tentang bangsa Indonesia merupakan bangsa yang rekat yang terdiri dari berbagai suku, namun selalu bersama untuk mencapai suatu keberhasilan. Iklan rokok ini disampaikan dalam bentuk monolog, karena pesan langsung disampaikan dari pembicara kepada pendengar atau penonton iklan rokok tersebut.bahasa yang digunakan adalah bahasa iklan

3. Analisis Iklan rokok Dunhill Filter 
Slogan taste the power. Situasi yang dalam iklan tersebut yaitu munculnya tulisan taste the power. Slogan iklan rokok Dunhill Filter menggunakan istilah asing yaitu taste the power. Jika dimaknai secara leksikal, taste berarti berasal dari bahasa Inggris yang berarti rasa sedangkan the power juga berasal dari bahasa Inggris yang berarti kekuatan. Apabila kedua kata tadi digabungkan menjadi taste the power, yang berarti rasa kekuatan. Bahasa yang digunakan dalam iklan tersebut adalah bahasa iklan. Bahasa tersebut diciptakan untuk menarik perhatian penonton.

\section{Analisis iklan rokok Djarum 76 Filter Gold}

Iklan rokok tersebut mempunyai slogan yang penting heppi.Situasi yang terjadi dalam iklan yaitu terjadinya percakapan antara jin dengan seorang gadis.Dimana sang gadis menyampaikan permintaannya kepada jin untuk memberikan seorang teman hidup, dengan santainya jin menjawab ok tapi ternyata yang muncul adalah seekor anjing lucu. Iklan tersebut disampaikan dalam bentuk dialog, Karena terjadi percakapan antara gadis dan jin. Bahasa dalam iklan tersebut menggunakan bahasa iklan. Dikatakan menggunakan bahasa iklan karena tidak ada keterkaitan antara produk diiklankan dengan tayangan.

\section{Analisis iklan rokok Magnum Filter}

Iklan rokok mempunyai slogan inspirasi tanpa batas. Situasi yang terjadi dalam iklan yaitu pertemuan dua orang pemuda bersahabat yang menikmati keindahan kota. Iklan rokok ini disampaikan dalam bentuk monolog, karena pesan langsung disampaikan dari pembicara kepada pendengar atau penonton iklan rokok tersebut.Iklan rokok magnum filter sama halnya dengan iklan yang lain, menggunakan bahasa iklan yang unik.

6. Analisis iklan U Mild

Iklan rokok mempunyai slogan Cowo lebih tau. Iklan rokok ini disampaikan dalam bentuk monolog, karena pesan langsung disampaikan dari pembicara kepada 
pendengar atau penonton iklan rokok tersebut.Iklan rokok magnum filter sama halnya dengan iklan yang lain, menggunakan bahasa iklan yang unik.

\section{Analisis iklanDunhill Mild}

Slogan dalam iklan adalah discover fine taste. Iklan rokok Dunhill Mild menggunakan istilah asing yaitu discover fine taste Jika dimaknai secara leksikal, discover berarti berasal dari bahasa Inggris yang berarti perubahan, fine berarti baik, sedangkan taste berarti rasa. Apabila ketiga kata tadi digabungkan menjadi discover fine taste, yang berarti rasa perubahan baik. Secara kontekstual, makna tersebut mempunyai arti bahwa menghisap rokok Dunhild Mild itu dapat memberikan perubahan baik. Dari segi penyampaian kepada penonton tampak tidak adanya keterkaitan antara produk dan tayangan iklan. Namun dari segi kata-kata yang digunakan dalam slogan iklan rokok tersebut tergolong menarik dan mudah diingat masyarakat.

\section{Analisis iklan Sampoerna A Mild}

Slogan dalam iklan adalah go ahead. Situasi yang terjadi dalam iklan yaitu sekelompok pemuda yang sedang lomba balapan motor di jalan raya, tidak disengaja seorang pemuda menyambar kaca spion mobil sehingga kaca spion tersebut patah. Namun akhirnya pemuda menitipkan nomor teleponnya diatas mobil tersebut. Slogan iklan rokok Sampoerna A Mild menggunakan istilah asing yaitu go ahead. Jika dimaknai secara leksikal, Go berarti berasal dari bahasa Inggris yang berarti pergi sedangkan ahead juga berasal dari bahasa Inggris yang berarti kedepan. Apabila kedua kata tadi digabungkan menjadi go ahead, yang berarti pergi kedepan. Meskipun slogan tersebut hanya menggunakan kalimat pendek yang terdiri atas dua kata, namun dapat dikatakan sebagai bahasa iklan. 


\section{Analisis iklan Gudang Garam Gold}

Iklan rokok tersebut mempunyai slogan cita rasa tinggi dengan sentuhan

emas. Situasi yang terjadi dalam iklan rokok yaitu 3 orang pemuda berpetualang dari suatu desa ke desa untuk menikmati pemandangan alam serta menikmati hasil kekayaan desa tersebut Iklan tersebut disampaikan dalam bentuk monolog dengan menggunakan bahasa iklan. Tidak ada hubungan antara produk yang diiklankan dengan tayangan pada iklan, sehingga iklan tersebut dikatakan menggunakan bahasa iklan.

Tabel Rekapitulasi Hasil Analisis Data

\begin{tabular}{|c|c|c|c|c|c|}
\hline \multirow{2}{*}{ No } & \multirow{2}{*}{$\begin{array}{l}\text { Nakma } \\
\text { Produk }\end{array}$} & \multirow{2}{*}{$\begin{array}{l}\text { Teks Iklan } \\
\text { Rokok }\end{array}$} & \multicolumn{2}{|r|}{ Makna } & \multirow{2}{*}{ Maksud } \\
\hline & & & Leksikal & Gramatikal & \\
\hline 1. & GG Signature & $\begin{array}{l}\text { Signature } \\
\text { Moment }\end{array}$ & $\begin{array}{l}\text { Waktu } \\
\text { Singkat }\end{array}$ & $\begin{array}{l}\text { Dengan menghisap } \\
\text { GG signature } \\
\text { memberikan } \\
\text { pemikiran singkat } \\
\text { untuk suatu tujuan } \\
\end{array}$ & $\begin{array}{l}\text { Waktu pemikiran } \\
\text { singkat untuk } \\
\text { mencapai suatu } \\
\text { tujuan }\end{array}$ \\
\hline 2. & Djisamsoe/234 & $\begin{array}{l}\text { Mahakarya } \\
\text { Indonesia }\end{array}$ & $\begin{array}{l}\text { Hasil } \\
\text { Karya }\end{array}$ & $\begin{array}{l}\text { Djisamsoe merupakan } \\
\text { rokok hasil karya } \\
\text { Indonesia }\end{array}$ & $\begin{array}{l}\text { Djisamsoe adalah } \\
\text { salah satu rokok } \\
\text { hasil karya } \\
\text { bangsa Indonesia }\end{array}$ \\
\hline 3. & Djarum Super & $\begin{array}{l}\text { My life My } \\
\text { Adventure }\end{array}$ & $\begin{array}{l}\text { Hidupku } \\
\text {, } \\
\text { petualan } \\
\text { ganku }\end{array}$ & $\begin{array}{l}\text { Menghisap djarum } \\
\text { super merupakan } \\
\text { suatu kebutuhan hidup }\end{array}$ & $\begin{array}{l}\text { Djarum super } \\
\text { memberikan } \\
\text { kenikmatan rasa } \\
\text { dalam setiap } \\
\text { hisapannya } \\
\end{array}$ \\
\hline 4. & $\begin{array}{l}\text { Djarum } 76 \text { Filter } \\
\text { Gold }\end{array}$ & $\begin{array}{l}\text { Yang } \\
\text { Penting } \\
\text { Hepi }\end{array}$ & $\begin{array}{l}\text { Bahagia, } \\
\text { senang }\end{array}$ & $\begin{array}{l}\text { Jangan takut untuk } \\
\text { menghisap rokok } \\
\text { Djarum } 76 \text { karna } \\
\text { setiap hisapannya } \\
\text { membuat kita bahagia }\end{array}$ & $\begin{array}{l}\text { Menghisap rokok } \\
\text { ini membuat kita } \\
\text { lebih bahagia }\end{array}$ \\
\hline 5. & Magnum Filter & $\begin{array}{l}\text { Inspirasi } \\
\text { Tanpa Batas }\end{array}$ & $\begin{array}{l}\text { Magnum } \\
\text { Filter } \\
\text { terus } \\
\text { mengha }\end{array}$ & $\begin{array}{l}\text { Menghisap Magnum } \\
\text { Filter selalu } \\
\text { menghadirkan } \\
\text { inspirasi tiada henti }\end{array}$ & $\begin{array}{l}\text { Setiap hisapan } \\
\text { rokok Magnum } \\
\text { menghadirkan } \\
\text { inspirasi yang }\end{array}$ \\
\hline
\end{tabular}




\begin{tabular}{|r|l|l|l|l|l|}
\hline 6. & U Mild & $\begin{array}{l}\text { Cowo } \\
\text { Lebih Tau } \\
\text { inspirasi }\end{array}$ & $\begin{array}{l}\text { Cowo } \\
\text { yang } \\
\text { lebih } \\
\text { tau }\end{array}$ & $\begin{array}{l}\text { Cowo U Mild yang } \\
\text { lebih tau dalam hal } \\
\text { merokok }\end{array}$ & $\begin{array}{l}\text { U Mild adalah } \\
\text { rokokknya cowo } \\
\text { karna cowo lebih } \\
\text { tau }\end{array}$ \\
\hline 7. & Dunhill Mild & $\begin{array}{l}\text { Discover } \\
\text { fine taste }\end{array}$ & $\begin{array}{l}\text { Rasa } \\
\text { perubah } \\
\text { an baik }\end{array}$ & $\begin{array}{l}\text { Dunhill Mild } \\
\text { memberikan rasa } \\
\text { perubahan dalam } \\
\text { setiap hisapannya }\end{array}$ & $\begin{array}{l}\text { Menghisap } \\
\text { Dunhill Mild } \\
\text { dapat } \\
\text { memberikan } \\
\text { perubahan baik }\end{array}$ \\
\hline 8. & A Mild & Go Ahead & $\begin{array}{l}\text { Pergi } \\
\text { kedepa } \\
\text { n }\end{array}$ & $\begin{array}{l}\text { Rokok A Mild } \\
\text { mengarahkan selalu } \\
\text { untuk kedepan }\end{array}$ & $\begin{array}{l}\text { Rokok A Mild } \\
\text { mengarahkan } \\
\text { kita untuk selalu } \\
\text { melangkah } \\
\text { kedepan }\end{array}$ \\
\hline 9. & GG Gold & $\begin{array}{l}\text { Cita Rasa } \\
\text { Tinggi } \\
\text { dengan } \\
\text { Sentuhan } \\
\text { Emas }\end{array}$ & $\begin{array}{l}\text { Memilik } \\
\text { i rasa } \\
\text { sentuhan } \\
\text { yang } \\
\text { tinggi }\end{array}$ & $\begin{array}{l}\text { Gudang Garam } \\
\text { adalah rokok yang } \\
\text { sudah tidak asing } \\
\text { lagi, baik nama } \\
\text { produknya maupun } \\
\text { rasanya }\end{array}$ & $\begin{array}{l}\text { Gudang garam } \\
\text { adalah rokok } \\
\text { yang memiliki } \\
\text { cita rasa yang } \\
\text { tinggi. }\end{array}$ \\
\hline
\end{tabular}

Berdasarkan analisis, iklan yang disiarkan melalui televisi merupakan salah satu cara produsen untuk menarik perhatian minat konsumen pada produk yang di iklankan. Berdasarkan data yang terkumpul, semua iklan rokok tersebut mempunyai makna kontekstual. Slogan yang dimunculkan pada iklan rokok dianggap unik. Makna kontekstual yang terdapat pada setiap iklan pada intinya berupa menarik perhatian konsumen.

Meskipun konsumen tahu bahwa kandungan nikotin dalam rokok sangat berbahaya bagi kesehatan, konsumen seolah tidak terpengaruhi. Bahkan disamping iklan rokok mengeluarkan slogan yang intinya mendorong konsumen untuk membeli. produk iklan juga mencantumkan ultimatum tentang bahaya rokok, yaitu merokok dapat menyebabkan kanker, impotensi, serangan jantung, gangguan kehamilan dan janin. Pernyataan ini seolah dianggap angin lalu sebagian orang yang gemar merokok. 
Dalam hal ini, bahasa memiliki peranan penting dalam periklanan. Pemakaian bahasa dalam iklan ini dikatakan sebagai bahasa iklan yang tidak terlepas dari faktor sosial dan situasional seperti halnya iklan rokok yang slogannya tidak ada keterkaitannya dengan rokok. Yang terpenting pada iklan rokok, yaitu bagaimana menarik perhatian konsumen. Masyarakat pada umumnya kurang memahami slogan iklan rokok. Mereka mencoba meraba-raba maksud dan tujuan iklan rokok tersebut. Ternyata iklan rokok di televisi memiliki makna kontekstual. Makna kontekstual tersebut tidak akan terwujud tanpa dua faktor yaitu faktor sosial dan situasional. Ketidakpahaman masyarakat terhadap slogan iklan rokok di televisi di sebabkan oleh kurang mengenanya pesan tersebut di hati masyarakat sehingga iklan rokok tersebut tidak komunikatif. Penayangan iklan rokok di televisi di tampilkan pada waktu tertentu, yaitu pada malam hari di mulai sekitar pukul 22.00 WITA. Alasan yang paling mendasar dari penayangan tersebut karena pada malam hari tontonan televisi di peruntukkan khusus untuk orang dewasa.

\section{PENUTUP}

\section{A. Simpulan}

Berdasarkan hasil penelitian yang telah di kemukakan pada bab IV sebelumnya, dapat di tarik sebuah simpulan bahwa:

1. Teks iklan rokok yang memilki makna kontekstual, antara lain GG Signature, Djisamsoe, Djarum Super, Djarum 76 Filter Gold, Magnum Filter, U Mild, Dunhill Mild, A Mild, GG Gold.

2. Iklan rokok yang muncul tersebut mempunyai makna kontekstual. Setiap slogan pada iklan rokok dianggap unik dan dapat menarik perhatian konsumen.

\section{B. Saran}

Berdasarkan hasil penelitian ini, maka perlu dikemukakan beberapa saran yaitu sebagai berikut : 
1. Penulis menyarankan kepada pembaca agar mengetahui tentang perkembangan ilmu bahasa, khususnya di bidang kajian semantik agar dapat bermanfaat dalam pengajaran bahasa dan sastra Indonesia ke depannya.

2. Penulis menyarankan kepada pembaca bahwa bahasa periklanan memiliki gambaran tentang makna kontekstual dalam iklan rokok di Televisi.

\section{DAFTAR PUSTAKA}

Alwasilah, A. Chaedar.2003.Pokoknya Kualitatif.Jakarta:Pustaka Jaya.

Aminuddin.2003.Semantik Pengantar Studi TentangMakna.Bandung:Sinar Baru Algensindo.

Best.2005.Penelitian Kualitatif,

(online)http://id.wikipedia.org/wiki/PenelitianKualitatif,26 Mei 2014.

Charlie,L.1999.Bahasa Indonesia di Iklan TV:Bahasa Indonesia yang Baik dan Gimana Gitu.Jakarta:Gramedia.

DepartemenPendidikan dan Kebudayaan.2002.Kamus Besar Bahasa Indonesia.Jakarta:Balai Pustaka.

Hadiwidjoyo, P.1993.Kata dan Makna.Bandung:Angkasa.

Keraf, G.2007.Diksi dan Gaya Bahasa.Jakarta:PT Gramedia Pustaka Utama.

Parera, J. D.2004.Teori Semantik.Jakarta:Erlangga.

Tarigan, H. G.1986.Pengajaran Semantik.Bandung:Angkasa.

Waridah,E.2008.EYDdanSeputarKebahasa-Indonesiaan.Jakarta.KawanPustaka 